\title{
Parques Nacionais Brasileiros: relação entre Planos de Manejo e a atividade ecoturística
}

\author{
Anderson Alves Santos
}

\section{RESUMO}

As Unidades de Conservação (UCs) são de extrema importância para a manutenção do equilíbrio ambiental e para a pesquisa científica, sendo designadas como uma área protegida pelo Poder Público, criadas por meio de legislação específica. De acordo com a Lei Federal no 9.985/00, existe duas categorias de manejo de UCs: as de Uso Sustentável - atendendo a objetivos determinados, de modo a originar a preservação dos ecossistemas naturais onde se situam -, e as de Proteção Integral, que são áreas que objetivam a "manutenção dos ecossistemas livres de alterações causadas por interferência humana, admitido apenas o uso indireto dos seus atributos naturais". Nessa categoria de manejo estão inseridos os parques nacionais - PARNAS. A regulamentação de uso dos PARNAS é regida pela legislação pertinente, que institui a obrigatoriedade de implantação e implementação do plano de manejo, além de outras diretrizes necessárias ao seu bom funcionamento e manutenção ambiental. Como o parque nacional se destina ao uso público, tendo a atividade turística de natureza como uma de suas principais inserções, as ações para a exploração de serviços turísticos devem estar previstas nos planos de manejo, de forma a possibilitar ao visitante o melhor aproveitamento de sua estada nos PARNAS. No presente trabalho abordar-se-á a legislação ambiental no tocante à criação dos planos de manejo e sua importância atrelada à atividade turística. Para isso serão abordadas a gênese legal e formatação de um plano de manejo, para em seguida confrontar a situação atual dos PARNAS brasileiros em relação à existência ou não de planos de manejo, apresentando a relação de PARNAS com planos de manejo e sua relação com a atividade turística. A metodologia de pesquisa para o presente trabalho se baseou nas respostas fornecidas pelos chefes de 57 PARNAS - embora existam hoje 66 parques - aos questionários semi-estruturados enviados aos mesmos por meio eletrônico.

PALAVRAS-CHAVE: Parques nacionais, Ecoturismo, Planos de manejo. 


\section{Brazilian National Parks: relationship between management plans and ecotour- ism activity.}

\section{ABSTRACT}

The conservation areas - UCs - are extremely important for maintaining the environmental balance and for scientific research, being designated as a protected area by the government, created through specific legislation. According to federal Law $n^{\circ}$ 9.985/00, there are two categories of management of protected areas: the sustainable use - given certain goals, to lead the preservation of natural ecosystems where they stand - and the Integral Protection, which are areas that focus on the "maintenance of ecosystems free of changes caused by human interference, admitted only the indirect use of its natural attributes." In this category of management are included Brazilian national parks - PARNAS. The regulation of the use of PARNAS is governed by applicable law, establishing the obligation of establishing and implementing the management plan, and other policies necessary for its proper operation and maintenance environment. As the national park is intended for public use, and the nature of tourism as one of its major insertions, actions for the operation of tourism services must be provided in management plans, to enable the visitor the best use of their stay in the national park. In the present study will address the environmental legislation regarding the creation of management plans and its importance attached to tourism. We shall address the legal genesis and formatting of a management plan, then confronting the current situation of Brazilian PARNAS regarding the existence or otherwise of management plans, showing the relationship of PARNES with management plans and their relationship to tourism. There search methodology for this study was based on responses provided by the heads of 57 PARNAS - although there are now 66 parks the semi-structured questionnaires sent to them electronically.

KEYWORDS: National Parks, Ecotourism, Management Plans.

\section{Introdução}

As Unidades de Conservação - termo utilizado no Brasil para designar 'áreas protegidas' - são áreas destinadas à proteção ambiental direcionadas a uso público em categorias específicas, tendo como exemplo mais abrangente, no Brasil, os parques nacionais - PARNAS. Para que sejam atrativos e cumpram sua função social, os parques nacionais devem possuir uma infraestrutura de apoio aos seus visitantes, bem como manterem o ambiente em seu interior o mais preservado possível. Para isso utiliza-se de planos de manejo com o intuito de apoiar tais ações, implementando uma visitação de mínimo impacto e ao mesmo tempo, apoiando a manutenção do próprio parque. Segundo dados oficiais, no Brasil, atualmente, os parques nacionais não recebem tantos visitantes quanto poderiam e, mesmo assim, essas visitas são concentradas em poucos deles. Ademais, dos 57 PARNAS respondentes, apenas 23 
são abertos à visitação (40,35\%), sendo $15(65,22 \%)$ com cobrança de tarifas e 08 $(34,78 \%)$ com entrada franca para turistas.

Como embasamento para o presente trabalho, busca-se apresentar um breve relato sobre a Legislação Ambiental referente aos parques nacionais brasileiros PARNAS, apresentando a gênese legal e formatação de um plano de manejo. Após isso, efetuar-se-á a confrontação da situação atual dos PARNAS brasileiros em relação à existência ou não de planos de manejo, apresentando a relação de PARNAS possuidores de planos de manejo, relacionando-os com a atividade turística.

Este trabalho tem como objetivo geral diagnosticar a situação atual dos Parques Nacionais - PARNAS - brasileiros em relação ao ecoturismo e se os planos de manejo contemplam essa atividade, verificando a possibilidade de implantação do ecoturismo nestas áreas.

\section{Revisão da literatura}

É sabido que a conservação dos recursos naturais é de fundamental importância para a manutenção do equilíbrio ambiental de uma determinada região. Tal percepção é antiga - data dos antigos impérios indianos a preocupação em manter reservas de caça para os imperadores. Com o desenvolvimento das comunidades, essa preocupação se direcionou para outros pontos, considerados, então, mais importantes, como a preservação de fontes de água. Dessa forma, foram criadas as áreas protegidas, com finalidades específicas, tais como a preservação de belezas cênicas, lugares de descanso para a população, preservação dos recursos ambientais etc.

Apenas em princípios do século XIX a ideia moderna de parque nacional surgiria nos Estados Unidos, por meio de um pequeno grupo de pessoas, objetivando proteger as maravilhas do país da exploração de poucos indivíduos e mantidas para usufruto de todos, como sempre foram. Traduzindo, a ideia de parque tem uma intervenção do Estado no que diz respeito a garantir o direito da maioria em detrimento das ambições de uns poucos.

A partir do século XIX foram registradas as primeiras intenções de criação de áreas legalmente protegidas, com a finalidade de se preservar as paisagens naturais e os ecossistemas nelas incluídos. Tal motivação se baseia em duas ideias principais: 1) é decorrente da busca de identidade nacional dos países do Novo Mundo - motivando as transformações de suas paisagens em monumentos - o que não existia na Europa de então; 2) na afirmação da nova democracia, que ia contra o desfrutamento das belezas naturais que caracterizavam o Velho Mundo, pela elite (MORSELLO, 2006). O exemplo primário disso é a criação do Parque Nacional de Yellowstone, em 1872, nos EUA. Foi usada a expressão "parque nacional" por se entender, na época, que o que estava em jogo era uma área administrada pelo governo federal, protegida para a realização de atividades de lazer para as pessoas. 
Parques Nacionais Brasileiros: relação entre Planos de Manejo e a atividade ecoturística.

\section{Conceituação}

Conforme BRASIL (2008, s/p), Unidade de Conservação é

toda porção do território nacional, incluindo as águas territoriais, com características naturais de relevante valor, de domínio público ou propriedade privada, legalmente instituídas pelo poder público, com objetivos definidos e sob regimes especiais de administração, às quais se aplicam garantias adequadas de proteção.

$\mathrm{O}$ art. $2^{\circ}$, item I, do Sistema Nacional de Unidades de Conservação - SNUC conceitua Unidade de Conservação como

o espaço territorial e seus recursos ambientais, incluindo as águas jurisdicionais com características naturais relevantes, legalmente instituídas pelo Poder Público, com objetivos de conservação e limites definidos, sob regime especial de administração, ao qual se aplicam garantias adequadas de proteção.

Explicitando melhor, é toda área protegida que possui regras próprias de uso e manejo, objetivando a proteção de espécies da fauna e flora, tradições culturais, belezas cênicas e de dados científicos, dependendo de sua classificação.

As áreas naturais protegidas - também chamadas de 'Unidades de Conservação' - buscam, por meio de um plano de manejo específico, promover o uso diversificado destes recursos, além de conservar, preservar e incentivar a manutenção das espécies nativas e/ou endêmicas. Para dirimir dúvidas a respeito destes dois termos - conservação e preservação -, segue uma breve explanação sobre os mesmos.

Quando usado o termo 'conservação', tem-se em mente que se está resguardando de dano, evitando a deterioração, o prejuízo. Assim, a conservação permite que haja a intervenção humana - até explorando alguns recursos naturais. Quando ela é percebida em relação ao meio ambiente, tem a conotação de proteção dos recursos naturais, utilizando-os racionalmente.

Quando se usa o termo 'preservação', deve-se entender como uma forma de garantir a integridade de alguma coisa. Tal termo é usado ao se referir à proteção integral, como forma de manter sua intocabilidade. Ao se levar em conta o meio ambiente, usa-se da preservação para evitar perda de biodiversidade constante nesse locus. Ou seja: a conservação incorpora melhorias ao meio ambiente, retardando sua degradação; e a preservação é uma ação direcionada à proteção integral das condições naturais dos recursos ambientais existentes. Conforme o entendimento de Vianna (2008, p.131), o "estabelecimento de áreas naturais protegidas tem sido uma das principais estratégias de conservação in situ no mundo". 
Assim, além da conservação, faz-se necessário também a preservação destas áreas naturais. Dessa forma, tornou-se comum a criação de Unidades de Conservervação/áreas protegidas, vislumbrando a proteção de diferentes recursos naturais e culturais, bem como da representatividade da flora e fauna regionais. Estas unidades se caracterizam basicamente por serem um espaço territorial que se destaca em razão de um conjunto ímpar e representativo de características naturais de valor relevante; por serem legalmente constituídas para a proteção destes respectivos recursos; por possuírem regimes específicos de gestão e por serem permanentes. De acordo com Rocktaeschel (2006, p.14), "a evolução do conceito de Unidade de Conservação (UC) relaciona-se com o desenvolvimento da ciência, a destruição da natureza e a busca cada vez maior do resgate do contato com a natureza".

\section{Breve histórico mundial das UCs}

Como colocado por Bensusan (2006) e Diegues (1994) a origem da percepção de espaços protegidos "intocados" está associada aos mitos judaico-cristãos de "paraíso".

Devido à degradação ambiental em fins do século XVIII, fomentada, de certa forma, pela explosão demográfica e pela Revolução Industrial, surge uma consciência mais cuidadosa, mais severa em relação a observações do que as "modernidades" de então ocasionavam ao planeta, principalmente no tocante à degradação, à qualidade de vida e, por que não, em relação às gerações vindouras. Por isso, Vianna (2008, p.139) afirma que "surge uma certa concepção de finitude da natureza expressa inclusive na decretação dos parques de caça, em que se revela a preocupação de se reservarem recursos específicos, finitos, para usufruto de uma elite, com fins recreativos".

Ost (1998, p.112), afirma que "advém da vontade de proteção de certas espécies espetaculares, em vias de extinção, e de grandes espaços virgens de toda a intervenção humana, a Convenção relativa à conservação da fauna e da flora no estado natural em África, assinada em Londres em novembro de 1933", sendo este "o texto que consagra pela primeira vez a noção de espécie ameaçada de extinção" e trata da instituição de reservas naturais e parques nacionais. No Brasil, a expressão "Unidade de Conservação" (UCs) designa as áreas naturais protegidas. As UCs são áreas chanceladas por órgãos ambientais e com alguma correspondência com as categorias internacionais, conforme é o entendimento de Bensusan (2006).

Brito (1995) afirma que os primeiros parques nacionais brasileiros vinculavamse ao conceito de monumentos públicos naturais e que, segundo a Constituição de 1937, visavam resguardar porções do território nacional que tivessem valor científico e estético. Na década de 1940 aparecem medidas legais inovadoras como, por exemplo, o Decreto $n^{\circ} 16.677 / 44$, que definiu como atribuições dos parques nacionais "conservar, para fins científicos, educativos, estéticos ou recreativos, as áreas sob jurisdição". Configura-se, dessa forma, que a função do parque se prestava a atender 
Parques Nacionais Brasileiros: relação entre Planos de Manejo e a atividade ecoturística.

às necessidades da sociedade moderna e urbana brasileira.

No Brasil, as Unidades de Conservação são organizadas em duas categorias de manejo - uma, de Proteção Integral e outra, de Uso Sustentável -, atendendo, primeiramente, a objetivos determinados, de modo a originar a preservação dos ecossistemas naturais onde se situam. As Unidades de Proteção Integral, conforme 0 art. $2^{\circ}$, inc. VI, da Lei $n^{\circ} 9.985 / 00$, são áreas onde há "manutenção dos ecossistemas livres de alterações causadas por interferência humana, admitido apenas o uso indireto dos seus atributos naturais".

\section{Gênese das Unidades de Conservação brasileiras}

O Brasil é considerado um dos países que demorou mais tempo a aceitar o conceito internacional de criação de áreas protegidas - no sentido de parques nacionais - incentivado pelas ideias de André Pinto Rebouças. Entretanto, existem registros históricos que mostram que a Coroa Portuguesa empreendeu grandes esforços no sentido de proteção, gestão e controle de determinados recursos naturais, principalmente os que mais the interessavam em termos econômicos. Essas primeiras ações têm seu surgimento ainda no Período Colonial, com um controle mais direcionado, principalmente à madeira, por ser considerada um recurso militar de extrema importância: a construção de embarcações. Os exemplos disso são o "Regimento do paubrasil", de 1605 - considerado por muitos como uma das primeiras leis de proteção florestal -, e a Carta Régia, de 1797, que importava na necessidade de se precaver contra a destruição das matas brasileiras, evitando suas ruínas ou destruição, coibindo o corte não autorizado pela Coroa de algumas espécies (as chamadas "madeiras de lei").

André Rebouças, apesar de seu pioneirismo ético-conservacionista, foi inspirado mais pela criação de Yellowstone que por outra coisa no sentido de se criar parques nacionais no Brasil, em 1876. Primeiramente, ele sugeriu duas áreas: a llha do Bananal e uma grande área entre as Cataratas de Guairá e as de Foz do Iguaçu, mas não obteve êxito nessas indicações, pelo menos a princípio. Em 1911, Gonzaga de Campos, por meio de preparação de um mapa sobre os ecossistemas brasileiros, também reivindicava a criação de parques nacionais, desta vez com um melhor embasamento (RYLANDS; BR|ANDON, 2005). Andrade e Silva, em 1821, propôs a criação de um setor administrativo responsável pelas matas e bosques, e enfatizava a necessidade de utilização moderada dos recursos naturais do país (DIEGUES, 2008), tomando como base a grande destruição da Mata Atlântica, principalmente na Região Nordeste.

Os PARNAS brasileiros foram criados seguindo o modelo norte-americano, mas desconsiderando as comunidades que vivem dentro ou próximas aos mesmos, o que não é compatível com a realidade brasileira. Isto leva a ver o parque não como um patrimônio a ser protegido, mas como um inimigo, já que as pessoas ficam impossibilitadas a conviver de forma sustentável com a área.

O objetivo básico para se criar uma UC tem sido o de proteger a área natural 
das ações antrópicas capazes de desequilibrarem seus ecossistemas. Entretanto, atualmente, a orientação das UCs parece se direcionar para uma perspectiva de integração do homem com a natureza. Assim, no termo "área natural protegida" há uma dupla valência: ao mesmo tempo em que visa a proteção dos espaços naturais contra a ação humana, busca também benefícios para o próprio ser humano, seja pelos serviços ambientais proporcionados, seja pela "vingança" (?) que ela, a natureza, possa infringir ao homem (GIULIANI, 2005).

Para que uma área seja protegida dentro da legalidade, faz-se uso de instrumentos legais que classificam e coordenam a metodologia para que as respectivas áreas não sofram reveses, tais como destinação incorreta de sua finalidade. Um desses instrumentos é o Sistema Nacional de Unidades de Conservação - SNUC, criado pela Lei $n^{\circ}$ 9.985/00; o outro é o Plano de Manejo. Mas, antes de se aprofundar nesse tema, faz-se interessante descrever o desenvolvimento das UCs no Brasil.

Os três primeiros parques nacionais brasileiros foram criados entre 1937 e 1939, refletindo o princípio da preocupação mundial para a necessidade de delimitação de espaços naturais legalmente protegidos, originada com a criação do Yellowstone National Park (1872), nos Estados Unidos. A cadeia de áreas naturais protegidas legalmente iniciou-se com a criação dos Parques Nacionais do Itatiaia, da Serra dos Órgãos e do Iguaçu, que eram administrados pelo Serviço Florestal do Ministério da Agricultura. De 1940 a 1958 não houve a criação de novas Unidades de Conservação. Somente a partir de 1959 este processo foi retomado com a criação dos parques Araguaia, Ubajara e Aparados da Serra - todos estes destinados à proteção das belezas excepcionais existentes nestas áreas.

Com a transferência da capital federal para Brasília, vislumbrou-se a necessidade de preservação do cerrado. Dessa forma, foram criados, em 1961, os Parques de Brasília, da Chapada dos Veadeiros e das Emas. Entre 1960 e 1964, percebendo a necessidade de proteger algumas áreas de grande e especial beleza cênica - no tocante ao "patriotismo nacional" -, criaram-se mais alguns PARNAS: Caparaó (por abrigar a localização do Pico da Bandeira: à época como sendo o ponto culminante do Brasil); Monte Pascoal (abriga o Monte Pascoal, primeira terra avistada pela expedição de Cabral); Tijuca (área de florestas sobranceira à cidade do Rio de Janeiro); Sete Cidades (possui monumentos geológico-geomorfológicos excepcionais) e São Joaquim (uma das últimas áreas remanescentes de araucária). De 1965 a 1969 essa linha de criação de UCs foi esquecida. Em 1967 foi criado o Instituto Brasileiro do Desenvolvimento Florestal - IBDF, através do Decreto-Lei no 289 , sendo ele o responsável pela administração das unidades criadas até então, tendo ainda, como uma de suas atribuições, a criação de novas unidades - inclusive parques de caça (permitidos à época).

Em 1970 foi criada a primeira reserva biológica brasileira - Poço das Antas, no Estado do Rio de Janeiro - por ser o habitat original do mico-leão-dourado, ameaçado de extinção: daí a importância de sua criação. Esta era uma categoria inovadora de então, pois visava explicitamente à conservação da biota, à pesquisa e Educação Am- 
Parques Nacionais Brasileiros: relação entre Planos de Manejo e a atividade ecoturística.

biental, excluída a visitação para lazer. Ainda na primeira metade da década de 1970 iniciou-se o processo de criação de UCs na Região Norte (PARNA da Amazônia), visando, além de proteger as fronteiras, fomentar o desenvolvimento motivado por reflexos econômicos, políticos e sociais nesta região. Nessa mesma década foram criados os PARNAS Serra da Bocaina e Serra da Canastra (na Região Sudeste) e Pantanal Mato-grossense (no Centro-Oeste). Houve também uma "mudança" na visão do Instituto Brasileiro de Desenvolvimento Florestal - IBDF: começou a levar em consideração para a criação de UCs as áreas indicadas por trabalhos científicos especializados. Cabe ressaltar que em 1972 aconteceu em Estocolmo, Suécia, a Conferência Mundial sobre o Meio Ambiente Humano, realizada pelas Nações Unidas, o que foi um marco importante para as discussões sobre desenvolvimento e meio ambiente.

De 1980 a 1984 houve uma "explosão" de criação de UCs, com 33 novas unidades. Até esta época, as UCs eram criadas pelo IBDF. Entretanto, com a criação da Secretaria Especial de Meio Ambiente-SEMA, criou-se, também, por meio da Lei $n^{\circ}$ 6.902/81, uma nova categoria de manejo: as Estações Ecológicas. Em 2000, através da Lei $n^{\circ} 9.985$, foi criado o Sistema Nacional de Unidades de Conservação da Natureza - SNUC, que passou a ser o detentor das prerrogativas para criação de UCs.

Durante a segunda metade da década de 1980, criaram-se mais sete parques: Serra do Divisor, Chapada Diamantina, Lagoa do Peixe, Marinho de Fernando de Noronha, Grande Sertão Veredas, Chapada dos Guimarães, Superagui e Monte Roraima.

A criação do Instituto Brasileiro do Meio Ambiente e dos Recursos Naturais Renováveis - IBAMA - em 1989, englobou os dois órgãos que instituíam as UCs - IBDF e Secretaria Especial do Meio Ambiente - SEMA -, equiparando a política de criação das UCs de proteção integral; ou seja, caberia ao IBAMA, doravante, a decisão para criação de novas UCs.

Entre 1995 e 1999, foram criados mais oito parques nacionais, privilegiando o uso público, destacando-se o PARNA de llha Grande (como forma compensatória pela construção da UHE de Ourinhos/SP. Os outros foram: Cavernas do Peruaçu, Caparaó, Pau Brasil, Descobrimento, Jurubatiba, Viruá, Serra da Mocidade. De 2000 até o presente, foram criados os PARNAS: da Amazônia, Chapada das Mesas, Serra da Bodoquena, Serra da Cutia, Serra do Itajaí, Serra do Rio Pardo, Araucárias, Nascentes do Rio Parnaíba, das Sempre Vivas, Jericoacoara, Saint-Hilaire/Lange, Ubajara, Catimbau, Monte Pascoal, Campos Gerais, Tumucumaque. Todas as áreas criadas a partir de então levaram em consideração discussões em seminários, que recomendavam a criação de UCs a partir de biomas. Cabe ressaltar que nessa gênese destacouse somente a criação de PARNAS, por serem estes o mote do presente trabalho.

\section{Sistema Nacional de Unidades de Conservação - SNUC}

O SNUC é o instrumento organizador das áreas naturais protegidas que, planejado, manejado e gerenciado como um todo, poderá viabilizar os objetivos nacionais de conservação. Sua consolidação se concentra na conservação in situ da diversida- 
de biológica em longo prazo, centrando-a em um eixo fundamental do processo conservacionista. Ele estabelece a relação primária de complementaridade entre as diferentes categorias de UCs, organizando-as de acordo com os respectivos objetivos de manejo e tipos de uso, a saber: Proteção Integral e Uso Sustentado (SNUC, 2000). Para a criação desse instrumento, buscou-se apoio em leis anteriores, tais como no Novo Código Florestal e a Lei de Proteção à Fauna (Lei no 4.771/65 e Lei oㅜ 5.197/67, respectivamente), e no Decreto-Lei oㅡ 84.017/79, que regulamenta os Parques Nacionais Brasileiros. Estes instrumentos jurídicos forneceram-lhe a base legal necessária. A Lei no 6.938/81, que dispõe sobre a Política Nacional do Meio Ambiente, também ampara a criação de áreas protegidas.

As Unidades de Uso Sustentável - ou de uso direto -, são aquelas onde busca-se a conservação dos atributos naturais, sendo permitida a exploração de parte dos recursos disponíveis desde que seja em regime de manejo sustentável. Nestas unidades procura-se conciliar a preservação da diversidade biológica e dos recursos naturais com o uso sustentado de parte destes recursos. São integrantes deste tipo: as Florestas Nacionais, as Reservas Extrativistas, as Áreas de Proteção Ambiental e as Áreas de Relevante Interesse Ecológico. As Unidades de Proteção Integral - ou de uso indireto -, são aquelas onde prevalecerá a conservação dos atributos naturais, objetivando a preservação dos ecossistemas em estado natural e com o mínimo de alterações possíveis, sendo admitido apenas o uso indireto dos seus recursos naturais, excetuando-se os casos previstos em lei. Elas são compostas por: Estação Ecológica, Reserva Biológica, Monumento Natural, Refúgio da Vida Silvestre, Reservas Particulares do Patrimônio Natural e Parque Nacional/Estadual.

O SNUC, em seu art. $1^{\circ}$, estabelece os critérios e as normas para criação, implantação e gestão das UCs; e em seu art. $2^{\circ}$.

\section{Planos de manejo}

Com o intuito de melhor gerir as UCs, foram criados os planos de manejo, que a partir de bases técnicas e científicas, norteie os trabalhos dessa gestão. O Plano de Manejo foi estabelecido para os PARNAS por meio do Decreto $n^{\circ} 84.017 / 79$ e sua obrigatoriedade foi determinada pela Lei ${ }^{\circ} 9.985 / 00$, que criou o Sistema Nacional de Unidades de Conservação da Natureza (SNUC). Conceitualmente, essa Lei o qualifica como o documento técnico mediante o qual, com fundamento nos objetivos gerais de uma UC, se estabelece o seu zoneamento e as normas que devem presidir o uso da área e o manejo dos recursos naturais, inclusive a implantação das estruturas físicas necessárias à gestão da respectiva unidade. Conforme 0 art. $6^{\circ}$ do Decreto $\mathrm{n}^{\circ}$ 84.017/79,

entende-se por Plano de Manejo o projeto dinâmico que, utilizando técnicas de planejamento ecológico, determine o zoneamento de um Parque Nacional, caracterizando cada uma das suas zonas e propondo seu desenvolvimento físico, de acordo com suas finalidades. 
Parques Nacionais Brasileiros: relação entre Planos de Manejo e a atividade ecoturística.

De acordo com o inc. XVII, do art. $2^{\circ}$, cap. I, da Lei $n^{\circ}$ 9.985/00, que estabelece - SNUC, o Plano de Manejo é o "documento técnico mediante o qual, com fundamento nos objetivos gerais de uma Unidade de Conservação, se estabelece o seu zoneamento e as normas que devem presidir o uso da área e o manejo dos recursos naturais, inclusive a implantação das estruturas físicas necessárias à gestão da Unidade". Para o IBAMA (BRASIL, 2007), o conceito de Plano de Manejo se baseia na definição apresentada no Regulamento dos Parques Nacionais Brasileiros, o qual estabelece que "Plano de Manejo é um projeto dinâmico que, utilizando técnicas de planejamento ecológico, determina o zoneamento de uma Unidade de Conservação, caracterizando cada uma de suas zonas e propondo seu desenvolvimento físico, de acordo com suas finalidades, e estabelece diretrizes básicas para o manejo da Unidade".

Milano (2001), entende que o Plano de Manejo é resultado do planejamento e é considerado como uma técnica ou instrumento de organização de processos futuros que permite otimizar as ações destinadas a alcançar os objetivos propostos para a área. Ainda conforme este autor (2001), "neste contexto o Plano de Manejo, contendo as orientações e informações ao adequado desenvolvimento das atividades, constituise no documento pelo qual se guiará o gestor da área nos seus trabalhos de administração."

Para o SNUC, o Plano de Manejo é um documento técnico mediante o qual se estabelece o zoneamento e as normas que devem presidir o uso da área e o manejo dos recursos naturais, inclusive a implantação das estruturas físicas necessárias à sua gestão. Dessa forma, ele o define como "o documento técnico que estabelece as normas que devem regulamentar o uso da área e o manejo dos recursos naturais, estabelecendo as diretrizes gerais para implementação da unidade" (RESERVA EXTRATIVISTA CAZUMBÁ-IRACEMA, 2006). O Plano de Manejo consiste em um diagnóstico da UC, levando em consideração diversos aspectos, tais como: sociais, ambientais, históricos, etc., amparados por uma análise da atual situação da unidade, como por exemplo: as pressões, ameaças, oportunidades e potencialidades (alusão à Matriz SWOT). Ele inclui também o zoneamento, que regulamenta a ocupação territorial e uso dos recursos naturais, bem como estabelece as regras de convivência entre as populações locais do entorno das respectivas UCs.

A Fundação Florestal de São Paulo ( $\mathrm{s} / \mathrm{d}, \mathrm{s} / \mathrm{p}$ ) levanta a importância da confecção e existência do Plano de Manejo e de uma "padronização de métodos e procedimentos técnicos e a contratação de serviços especializados", a fim de garantir a qualidade dos mesmos, "definindo princípios comuns, métodos de levantamento de dados primários, de planejamento estratégico, nomenclaturas de programas de gestão e respectivas atividades."

Buscando garantir uma maior e melhor dinâmica ao planejamento das UCs de Proteção Integral, o Plano de Manejo foi idealizado para aplicação em três fases que buscam subsidiar a evolução dos conhecimentos sobre os recursos das respectivas UCs, bem como a ampliação das ações de manejo suportadas por este conhecimento. Essa aplicação em três fases torna o plano de manejo gradativo, contínuo, fle- 
xível e participativo, pelos seguintes motivos:

- Gradativo: a evolução dos conhecimentos sobre os recursos da UC, ao longo das três fases, condiciona a ampliação e o aprofundamento das ações de manejo sobre os seus recursos;

- Contínuo: cada nova fase sempre englobará os conhecimentos e as ações da fase anterior; além do que, cada nova fase será planejada já durante a implementação da fase anterior, não sendo interrompida;

- Flexível: sua estrutura possibilita a agregação de novos conhecimentos e eventuais correções ao manejo durante a implementação de qualquer das fases. As ações de monitoria e reavaliação efetuadas durante sua implantação indicarão a necessidade de se fazer ou não tais correções;

- Participativo: sua elaboração prevê o envolvimento da sociedade no planejamento, por meio das Oficinas de Planejamento; além disso, sua estrutura prevê ações no entorno das unidades, objetivando a cooperação das populações de entorno e a conseqüente melhoria de sua qualidade de vida.

A Figura 1 mostra um esquema do planejamento, facilitando uma melhor visualização do processo acima descrito, apontando a relação entre a ampliação do conhecimento e as ações de manejo para atuação em uma UC:

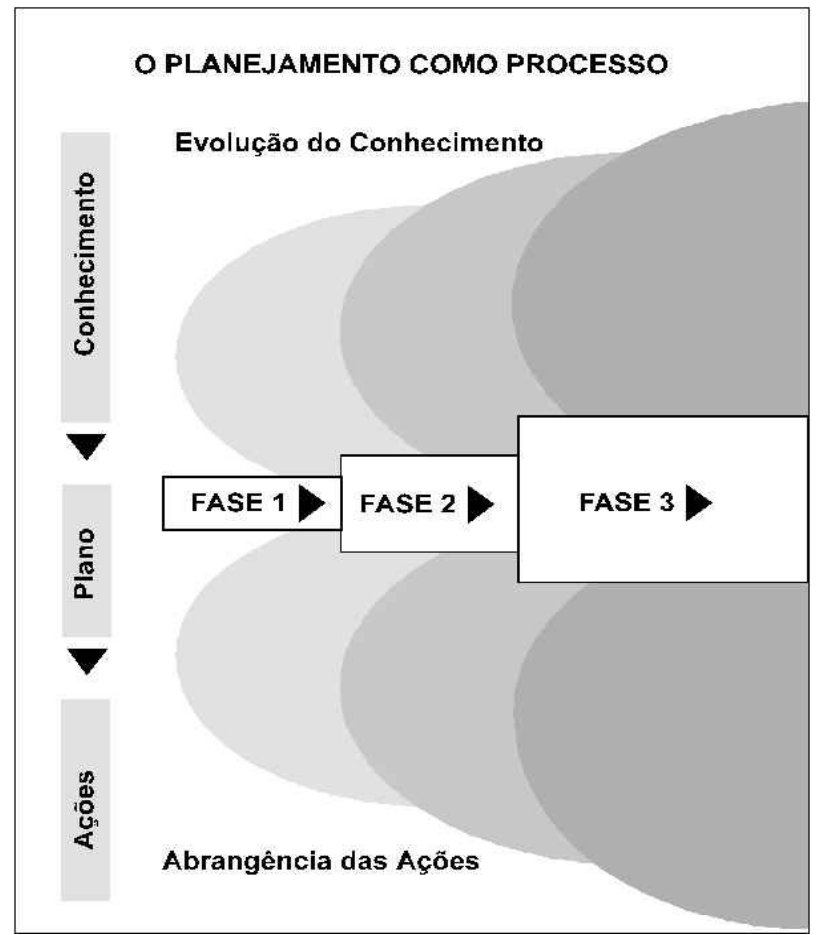

Figura 1 - O planejamento como processo. Fonte: BRASIL, 2004. 
Parques Nacionais Brasileiros: relação entre Planos de Manejo e a atividade ecoturística.

A Figura 2 - Principais enfoques das diferentes fases, abaixo, explicita cada uma das fases do Plano de Manejo:

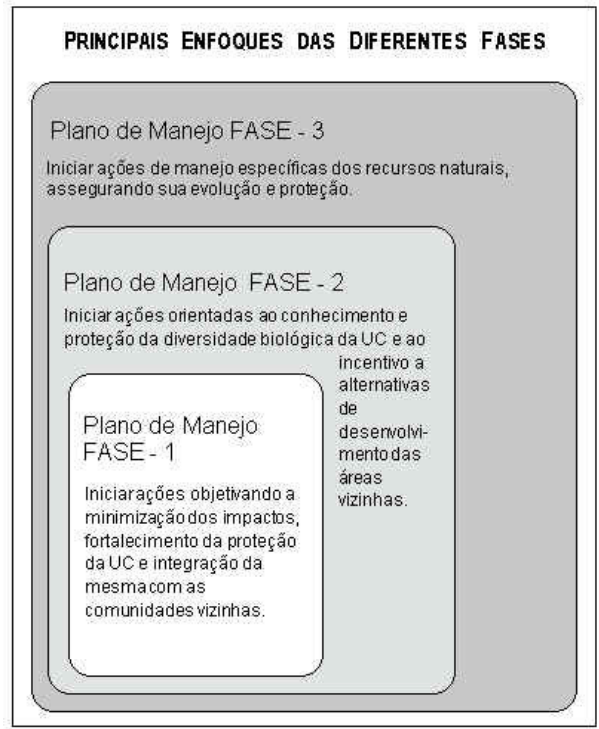

Figura 2 - Principais enfoques das diferentes fases. Fonte: BRASIL, 2004.

\section{Estrutura dos Planos de Manejo}

O Plano de Manejo se estrutura em oito encartes, nos quais a UC é enfocada a partir do contexto em que se encontra: federal, estadual ou regional. Conforme apresentado por BRASIL (2004), os encartes podem ser visualizados na Figura 3 - Estrutura do Plano de Manejo:

\section{ESTRUTURA DO PLANO DE MANEJO}

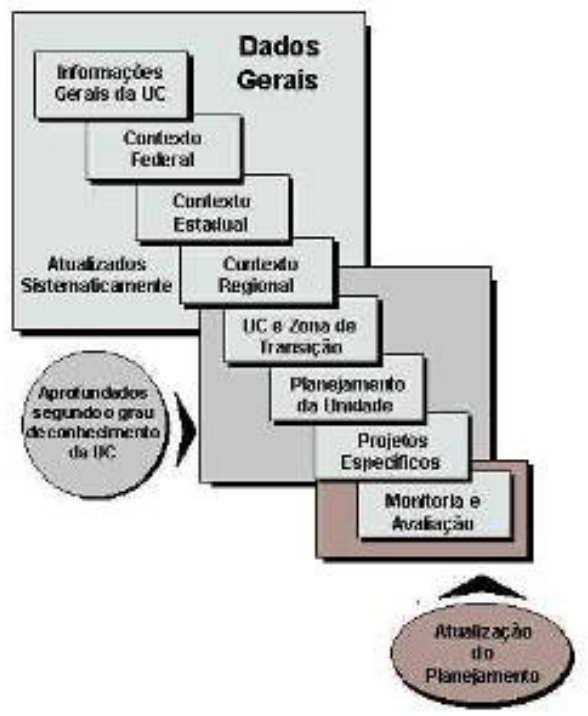

Figura 3 - Estrutura do plano de manejo. Fonte: BRASIL, 2004. 


\section{E qual o papel do Ecoturismo nessa discussão?}

Um dos principais objetivos para se fazer um plano de manejo para uma Unidade de Conservação - nesse caso específico, os PARNAS -, além da preocupação com a preservação ambiental, é a inclusão da sociedade. O Plano de Manejo seguirá os preceitos legais exigidos para sua confecção, direcionando os PARNAS para:

- a manutenção e preservação da biodiversidade existente nos PARNAS;

- a proteção e valorização dos recursos naturais usados para a subsistência das populações tradicionais de entorno dos respectivos parques, valorizandoas, bem como promovendo sua inclusão sócio-econômica;

- a inclusão, promoção e valorização da educação ambiental e do turismo de natureza - o Ecoturismo.

O Ecoturismo - é uma atividade em franco crescimento mundial. Sua prática é mais frequente em parques nacionais, devido principalmente à legislação - é uma das poucas categorias de UCs onde se é permitida sua execução - e também à infraestrutura que alguns parques possuem para atender a essa demanda.

As áreas naturais protegidas - e dentro destas, os PARNAS - poderão fazer uso do Ecoturismo organizado e de mínimo impacto, beneficiando economicamente essas áreas; mas, para isso o parque deve ser administrado, supervisionado e controlado rigorosamente por medidas de proteção para evitar a degradação provocada pelos turistas. Necessitam também de infra-estrutura e equipamentos que possibilitem a adequada exploração da atividade turística; entretanto, os chefes dos parques dispõem de poucos recursos para enfrentar a demanda crescente de turistas (PASQUALI, 2006).

Pelo entender de Barros e Dines (2000), haverá um aumento do número de visitantes que procuram as poucas áreas naturais remanescentes em função de uma complexa gama de condições, entre as quais: maiores facilidades de acesso, crescente disponibilidade e qualidade de equipamentos, divulgação maciça dessas áreas e atividades pelos meios de comunicação, e as oportunidades oferecidas para a prática de atividades recreativas e turísticas em áreas naturais protegidas, principalmente em parques. E, ainda, a busca pela natureza, o retorno às raízes, a vontade de visualizar a natureza ainda preservada. Rocktaeschel (2006, p.44) corrobora dessa visão ao afirmar que

parte-se do pressuposto de que, uma vez atraídos novos visitantes para determinadas áreas protegidas, com maior capacidade de recebimento de ecoturistas, serão criadas, regional e localmente, as condições básicas capazes de viabilizar e estimular a participação da iniciativa privada nessas novas oportunidades de negócios, por meio da prestação sistematizada de serviços aos turistas.

Desta forma, para que o turismo possa ser implantado e implementado nestas unidades, faz-se necessária uma abertura maior, amparada nos planos de manejo, que poderão abarcar em sua constituição a inserção de atividades turísticas, valorizado e capacitando a mão-de-obra do entorno destas unidades, bem como ampliando a 
Parques Nacionais Brasileiros: relação entre Planos de Manejo e a atividade ecoturística.

possibilidade de real uso público dos PARNAS, conforme previsto em lei.

$\mathrm{Na}$ compreensão de Kinker (2002), uma atividade só é classificada como sustentável quando tem como sustentáculo a análise do seu desenvolvimento em um determinado momento; ou seja, não há menção a garantias de sustentabilidade a longo prazo, possivelmente devido aos variados fatores e atores externos que interferem intencionalmente ou não - no planejamento sustentável do objeto em questão. Sendo - Ecoturismo considerado como um fenômeno cujas bases se amparam nos princípios de sustentabilidade e é bastante dependente de política pública, a autora (2002, p.15) ainda afirma que

o desenvolvimento sustentável do turismo não é um estado fixo de harmonia. È um processo de mudanças em que às alterações na utilização dos recursos, a gestão dos investimentos e a orientação do desenvolvimento em nível institucional são coerentes com as necessidades futuras e presentes e dependem de uma política ambiental e turística adequada.

Quando se trata de Ecoturismo, uma das principais bases para alcançar a sustentabilidade tanto dessa atividade quanto da natureza, é o Plano de Manejo, principalmente quando a área onde ele ocorre é um PARNA. Deve-se também levar em consideração o planejamento das empresas e ou órgãos públicos relacionados a essa atividade, pois todo o planejamento externo para visitação e uso é baseado no Plano de Manejo do respectivo PARNA, conforme explicitado no art. 28 do SNUC, que define que não são permitidas, "nas Unidades de Conservação, quaisquer alterações, atividades ou modalidades de utilização em desacordo com os seus objetivos, o seu plano de manejo e seus regulamentos."

\section{Materiais e Métodos}

O objeto de estudo do presente trabalho foram os 66 PARNAS brasileiros. Destes, três são parques não foram efetivamente implantados (Nascentes do Lago Jarí; Mapinguari e Rio Novo). Os três parques criados na Bahia em junho de 2010 (Serra das Lontras, Alto Cariri e Boa Nova) não serão analisados neste trabalho. Abrolhos, Viruá e Anavilhanas, que até o presente não se manifestaram, também não serão computados, restando então 57 PARNAS a serem analisados. A metodologia de pesquisa, exploratória e também descritiva, se baseou nas respostas fornecidas pelos chefes dos PARNAS a questionários enviados via e-mail.

Vasquéz (2005) afirma que a metodologia, sendo parte da ciência, se ocupa dos procedimentos necessários para alcançar os objetivos do conhecimento científico. Dessa forma, o método científico constitui o itinerário mediante o qual se alcançam conhecimentos rigorosos, corretos e seguros. E complementa: 
En líneas generales, el método de investigación cientifico es el iter procedimental a seguir para lograr o alcanzar el objetivo propuesto. Su punto de partida suele ser una teoria previa o un conjunto racional y sistemático de ideas sobre la realidad en cuestión, en otros términos, el cuerpo de conocimientos disponible, en cada momento del tiempo, que habitualmente constituye el origen de los problemas que formula y desarrolla el investigador (p.IV).

Este autor ainda cita Lakatos (1983) para embasar seu pensamento, afirmando que este postula o relativismo dos programas de investigação científica, ao considerar que estes não necessariamente tenham caráter científico sine die, podendo migrar de um estado progressivo a um degenerativo, ou vice-versa.

\section{Resultados e Discussão}

No Brasil, atualmente, os parques nacionais não recebem tantos visitantes quanto poderiam e, mesmo assim, essas visitas são concentradas em poucos parques. Ademais, dos 57 PARNAS respondentes, apenas 23 são abertos à visitação $(40,35 \%)$, sendo $15(65,22 \%)$ com cobrança de tarifas e $08(34,78 \%)$ com entrada franca para turistas. O Quadro 1 - Relação de PARNAS com planos de manejo e infra-estrutura para visitação, a seguir, dá uma visão mais clara da região onde se localizam tais parques e suas situações:

Quadro 1 - Relação de PARNAS abertos à visitação e com Planos de Manejo1

\begin{tabular}{|l|c|c|l|}
\hline $\begin{array}{c}\text { PARNA por região } \\
\text { (quantidade) }\end{array}$ & $\begin{array}{c}\text { Abertos à visita- } \\
\text { ção turística }\end{array}$ & $\begin{array}{c}\text { Com Plano } \\
\text { de Manejo }\end{array}$ & Observação \\
\hline Norte (20) & 02 & 06 & \\
\hline Nordeste (16) & 06 & 08 & Não são necessariamente os mesmos. \\
\hline Sudeste (12) & 07 & 09 & \\
\hline Sul (11) & 05 & 05 & Não são necessariamente os mesmos. \\
\hline Centro-Oeste (06) & 03 & 04 & Não são necessariamente os mesmos. \\
\hline Total & 23 & 32 & \\
\hline
\end{tabular}

${ }^{1}$ Considerando apenas os PARNAS respondentes, baseado em dados fornecidos pelos chefes dos PARNAS em 2009.

$\mathrm{Na}$ Figura 4, abaixo, pode-se ter uma melhor visualização da localização destes PARNAS. 
Parques Nacionais Brasileiros: relação entre Planos de Manejo e a atividade ecoturística.

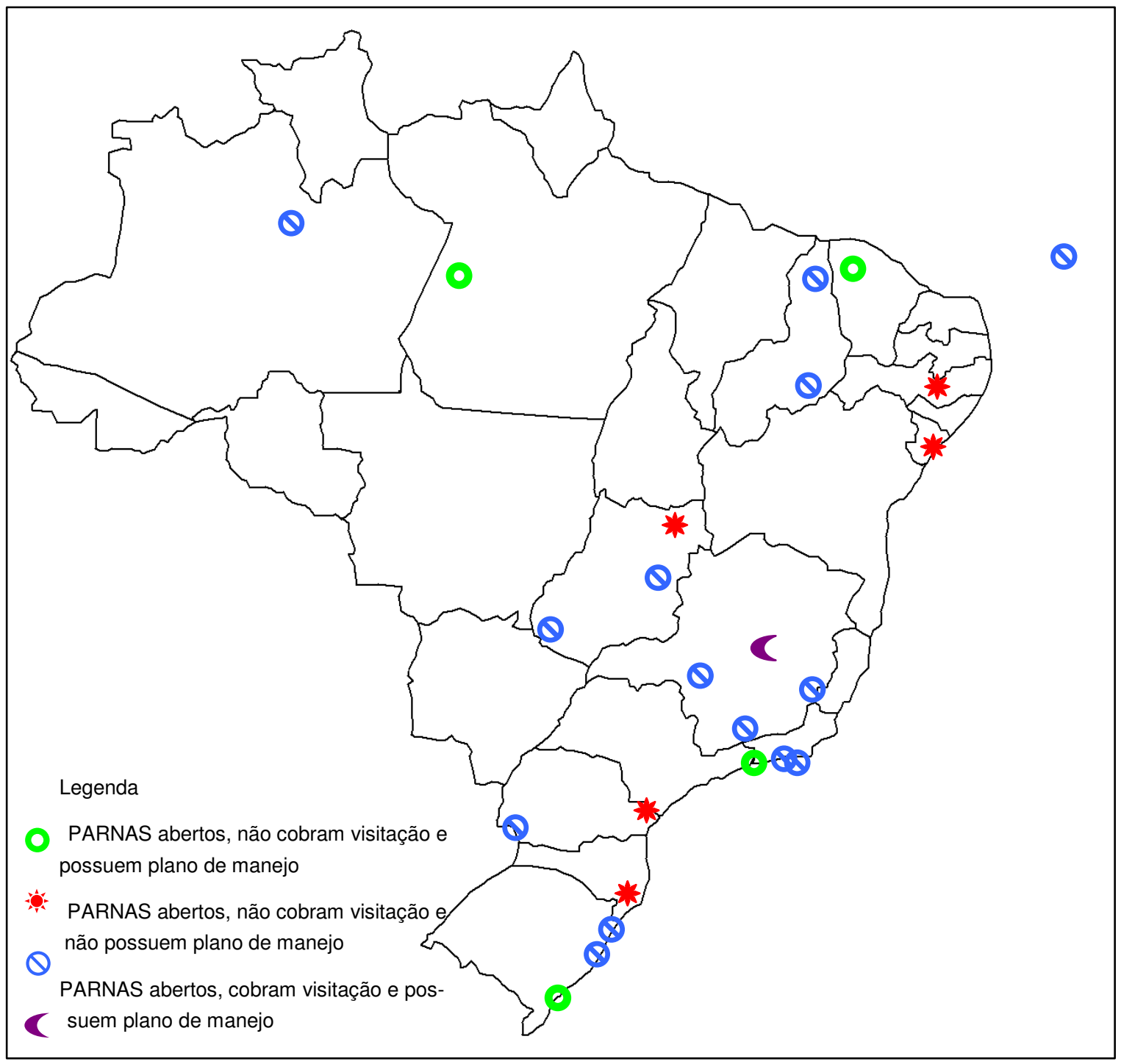

Figura 4 - PARNAS abertos a visitação, que cobram entrada e que possuem Planos de Manejo.

Dos 57 PARNAS respondentes, 25 (43,86\%) não possuem Planos de Manejo. Dos que o possuem, 22 (68,75\%) estão incompletos. Os dados existentes são poucos e, baseando-se nas respostas dos chefes, se encontram defasados. A questão de atualização ou mesmo existência dos referidos Planos de Manejo - bem como dos Conselhos Gestores e ou Consultivos; quantidade de funcionários efetivos e contratados; e relação área do PARNA/funcionário efetivo - poderá ser observada a seguir:

- $\quad$ Região Norte: 14 PARNAS respondentes, 06 PARNAS possuem Planos de Manejo - sendo o mais antigo de 1979 e o mais recente de 2006; dos respondentes, 05 possuem Conselhos Gestores/ Consultivos e destes um não é ativo; 
- $\quad$ Região Nordeste: 15 PARNAS respondentes, 08 PARNAS possuem Planos de Manejo, sendo os mais antigos de 1979 e o mais recente de 2009. Quanto aos Conselhos, seis os possuem em atividade;

- $\quad$ Região Sudeste: 11 PARNAS respondentes. Deles, apenas dois não possuem planos de manejo. Dos que possuem Plano de Manejo, o mais antigo é de 1981 e os mais recentes são de 2008. Em relação aos Conselhos, sete os possuem ativos, dois não os possuem e dois são inativos;

- $\quad$ Região Sul: 11 PARNAS respondentes. Destes PARNAS, seis não possuem Planos de Manejo e dos que o possuem, o mais antigo é de 2000 e os mais recentes são de 2008. Destes parques, cinco possuem Conselhos ativos, quatro não o possuem e no restante eles não são ativos;

- $\quad$ Região Centro-Oeste: 06 PARNAS respondentes, dos quais quatro possuem Planos de Manejo, sendo o mais antigo de 1998 e o mais recente data de 2005. Um deles não possui Conselho e dos restantes, dois não são ativos.

Dos PARNAS respondentes, um em especial, na Região Centro-Oeste, foi criado há mais de 48 anos e usa o Plano de Manejo de 1978; ou seja um plano com 30 anos de defasagem (em 1992 foi realizada a revisão do plano deste PARNA), contrariando o $\S 3^{\circ}$ da Lei $n^{\circ}$ 9.985/00, prevê que "o Plano de Manejo de uma Unidade de Conservação deve ser elaborado no prazo de cinco anos a partir da data de sua criação." Neste caso específico, o PARNA foi criado e 17 anos depois elaborou-se um Plano de Manejo e até o presente ele não foi retificado.

A Lei $n^{\circ} 9.985 / 00$, em seu art. $4^{\circ}$, instrui que o Plano de Manejo tem como objetivos, entre outros, o de "favorecer condições e promover a educação e interpretação ambiental, a recreação em contato com a natureza e o turismo ecológico". Entretanto, quando se verifica a relação dos PARNAS com Planos de Manejo e abertos à visitação versus a previsão de atividades turísticas nos respectivos parques, tem-se que:

- Região Norte: apenas um prevê atividade turística;

- Região Nordeste: somente quatro parques prevêem atividade turística;

- Região Sudeste: cinco parques prevêem atividades turísticas em seus planos;

- Região Sul: três parques prevêem, mas um deles informa falta de estrutura e alto índice de problemas;

- Região Centro-Oeste: apenas um parque prevê atividades turísticas.

O art. 11, desta mesma Lei, deixa claro que o objetivo básico de um parque nacional é "a preservação de ecossistemas naturais de grande relevância ecológica e 
Parques Nacionais Brasileiros: relação entre Planos de Manejo e a atividade ecoturística.

beleza cênica, possibilitando a realização de pesquisas científicas e o desenvolvimento de atividades de educação e interpretação ambiental, de recreação em contato com a natureza e de turismo ecológico." Este mesmo artigo, em seu $\S 2^{\circ}$, explicita a importância do Plano de Manejo em relação à visitação, ao sujeitá-la "às normas e restrições estabelecidas no Plano de Manejo da unidade, às normas estabelecidas pelo órgão responsável por sua administração, e àquelas previstas em regulamento."

E mais: o art. 51 desta mesma Lei é categórico ao afirmar que o Poder Executivo Federal submeterá à apreciação do Congresso Nacional, a cada dois anos, um relatório de avaliação global da situação das Unidades de Conservação federais do País. Esse é o chamado Relatório Parametrizado - um documento no qual constam todos os dados relacionados aos parques nacionais brasileiros - e que está defasado e incompleto, conforme a relação apresentada no Quadro 2 :

Quadro 2 - Relação de PARNAS por Região X Relatório Parametrizado ${ }^{2}$

\begin{tabular}{|l|c|c|c|c|}
\hline \multicolumn{1}{|c|}{ REGIÅO } & $\begin{array}{c}\text { Quantidade } \\
\text { de PARNAS }\end{array}$ & $\begin{array}{c}\text { Relatórios Pa- } \\
\text { rametrizados } \\
\text { COMPLETOS }\end{array}$ & $\begin{array}{c}\text { Relatórios Para- } \\
\text { metrizados IN- } \\
\text { COMPLETOS }\end{array}$ & $\begin{array}{c}\text { Relatórios Para- } \\
\text { metrizados SEM } \\
\text { DADOS }\end{array}$ \\
\hline NORTE & 20 & 01 & 04 & 15 \\
\hline NORDESTE & 16 & 01 & 01 & 14 \\
\hline SUDESTE & 11 & 02 & 05 & 04 \\
\hline SUL & 11 & 01 & 03 & 07 \\
\hline CENTRO-OESTE & 06 & 01 & 02 & 03 \\
\hline TOTAL & 66 & 06 & 15 & 45 \\
\hline Percentual & $100 \%$ & $9,09 \%$ & $22,73 \%$ & $68,18 \%$ \\
\hline
\end{tabular}

${ }^{2}$ Levando-se em consideração 63 PARNAS brasileiros em 2009.

Para que se tenha desenvolvimento é importante a observação das mudanças sócio-ambientais e o respeito às necessidades do ambiente em se manter atrativo à sociedade, que somente aprenderá a protegê-lo se puder ter um contato mais "íntimo" com essa natureza contida nos parques. Essa mesma proteção será conseguida com a Educação Ambiental não-formal - como aquela em que as ações e práticas educativas são voltadas à sensibilização da coletividade sobre as questões ambientais e à sua organização e participação na defesa da qualidade do meio ambiente -, e com mais interatividade, para aí sim, promover a utilização dos princípios e práticas de conservação da natureza no processo de desenvolvimento, bem como valorizar econômica e socialmente a diversidade biológica.

Conforme o entendimento de Quintas (2004, p.33), para que a Educação Ambiental cumpra sua finalidade - definida na Lei $n^{\circ}$ 9.795/99, que institui a Política Nacional de Educação Ambiental - ela deve favorecer as devidas condições 
para o desenvolvimento das capacidades necessárias para que grupos sociais, em diferentes contextos socioambientais, intervenham de modo qualificado, tanto na gestão do uso dos recursos ambientais, quanto na concepção e aplicação de decisões que afetam a qualidade do ambiente, seja físico-natural ou construído.

Para Souza (1997) o desenvolvimento sustentável se apresenta como um enorme desafio para a humanidade atual, quando se pensa apenas em termos mercadológicos, visando o lucro fácil. Em uma atividade econômica, o mote é pautado levando-se em consideração o binômio "maximização dos lucros X minimização dos custos"; assim, tudo mais que transcorre pelo processo produtivo é considerado como externalidade, que no entendimento de Moura (2005, p.21),

refere-se à ação que um determinado sistema de produção causa em outros sistemas externos. Trata-se de um conceito desenvolvido pelo economista inglês Pigou em 1920, que estabeleceu que existem externalidades quando a produção de uma empresa (ou um consumo individual) afeta o processo produtivo ou um padrão de vida de outras empresas ou pessoas, na ausência de uma transação comercial entre elas. Normalmente esses efeitos não são avaliados em termos de preços.

Também são poucos os parques que possuem um Conselho Gestor/Consultivo, previsto no art. 29 da Lei n 9.985/00: "cada Unidade de Conservação do grupo de Proteção Integral disporá de um Conselho Consultivo, presidido pelo órgão responsável por sua administração...”. é importante ressaltar que, na inexistência do Plano de Manejo ou até que ele seja implantado, cabe ao Conselho definir as prioridades e ou ações a serem realizadas no respectivo PARNA. O Quadro 3 apresenta a relação de PARNAS por região que possuem Conselhos e se os mesmos são ou não ativos:

Quadro 3 - Relação de PARNAS com Conselhos e sua participação ${ }^{3}$.

\begin{tabular}{|l|c|c|c|c|}
\hline REGIÃO & $\begin{array}{c}\text { Quantidade } \\
\text { de PARNAS }\end{array}$ & $\begin{array}{c}\text { Possuem Conse- } \\
\text { Ihos } \\
\text { ativos }\end{array}$ & $\begin{array}{c}\text { NÃO possu- } \\
\text { em Conse- } \\
\text { lhos }\end{array}$ & $\begin{array}{c}\text { Possuem Con- } \\
\text { selhos, mas não } \\
\text { são ativos }\end{array}$ \\
\hline NORTE & 14 & 05 & 08 & 01 \\
\hline NORDESTE & 15 & 06 & 08 & 01 \\
\hline SUDESTE & 11 & 05 & 04 & 02 \\
\hline SUL & 11 & 06 & 04 & 01 \\
\hline CENTRO-OESTE & 06 & 03 & 01 & 02 \\
\hline TOTAL & 57 & 25 & 25 & 07 \\
\hline Percentual & $100 \%$ & 43,86 & 43,86 & 12,28 \\
\hline
\end{tabular}

${ }^{3}$ Considerando apenas os PARNAS respondentes, baseado em dados fornecidos pelos chefes dos PARNAS em 2009. 
Parques Nacionais Brasileiros: relação entre Planos de Manejo e a atividade ecoturística.

Ao se efetuar a relação "PARNA com Conselho versus PARNA com visitação", tem-se o seguinte:

Quadro 4 - PARNA com Conselho versus PARNA com visitação ${ }^{4}$

\begin{tabular}{|l|c|c|c|l|}
\hline REGIÃO & $\begin{array}{c}\text { Quantidade } \\
\text { de PARNAS } \\
\text { responden- } \\
\text { tes }\end{array}$ & $\begin{array}{c}\text { PARNAS com } \\
\text { Conselho ativo }\end{array}$ & $\begin{array}{c}\text { PARNAS } \\
\text { abertos } \\
\text { à visitação }\end{array}$ & \multicolumn{1}{|c|}{ Observação } \\
\hline NORTE & 14 & 05 & 02 & $\begin{array}{l}\text { Não necessariamente } \\
\text { os mesmos }\end{array}$ \\
\hline NORDESTE & 15 & 06 & 06 & $\begin{array}{l}\text { Não necessariamente } \\
\text { os mesmos }\end{array}$ \\
\hline SUDESTE & 11 & 05 & 07 & $\begin{array}{l}\text { Não necessariamente } \\
\text { os mesmos }\end{array}$ \\
\hline SUL & 11 & 06 & 05 & $\begin{array}{l}\text { Não necessariamente } \\
\text { os mesmos }\end{array}$ \\
\hline CENTRO-OESTE & 06 & 03 & 03 & $\begin{array}{l}\text { Não necessariamente } \\
\text { os mesmos }\end{array}$ \\
\hline TOTAL & 57 & 25 & 23 & $\begin{array}{l}\text { Não necessariamente } \\
\text { os mesmos }\end{array}$ \\
\hline
\end{tabular}

${ }^{4}$ Considerando apenas os PARNAS respondentes, baseado em dados fornecidos pelos chefes dos PARNAS, 2009.

Como se pretende que haja o interesse de que o turismo seja ampliado ou incentivado numa UC que não se atualiza? Essa dúvida é embasada no art. 28 da respectiva Lei, em seu parágrafo único, que explicita:

Até que seja elaborado o Plano de Manejo, todas as atividades e obras desenvolvidas nas Unidades de Conservação de proteção integral devem se limitar àquelas destinadas a garantir a integridade dos recursos que a unidade objetiva proteger, assegurando-se às populações tradicionais porventura residentes na área as condições e os meios necessários para a satisfação de suas necessidades materiais, sociais e culturais.

Os PARNAS, não possuindo um Plano de Manejo atualizado e condizente com os novos tempos, estão sucessíveis a inúmeros problemas, tais como falta de planejamento sócio-turístico nas regiões de entorno, abrindo caminho para a depredação e caça predatória, queimadas e outros tipos de impactos negativos, além de não incentivar a melhoria da situação sócio-econômica da população de entorno dos mesmos. Conforme constante no Plano de Manejo do PARNA de Brasília (1992, p. 225) 
Os parques nacionais brasileiros - até hoje, apenas entes ambientais, tementes das demandas sociais - precisam se transformar em entes Político-Ambientais com a tripla função: social, preservacional e científica, até mesmo como estratégia para sua sobrevivência econômica e política.

\section{Para finalizar, algumas constatações alarmantes}

Poucos parques nacionais têm um Plano de Manejo e ou estão abertos à visitação, seja por falta de investimento ou por não contemplarem a atividade turística na formatação desses planos;

Como é incentivada na Legislação ambiental referente aos parques nacionais a existência de um Conselho até a aprovação do respectivo Plano de Manejo para deliberar sobre as atividades realizadas em sua área, poucos parques possuem um Conselho ativo;

Apenas seis parques nacionais possuem seu relatório parametrizado completo.

\section{Referências Bibliográficas.}

BARROS, M.I.A; DINES, M. Mínimo Impacto em Áreas Naturais: uma mudança de atitude. In: SERRANO, C. (Org.). A educação pelas pedras: Ecoturismo e educação ambiental. São Paulo: Chronos, 2000.

BENSUSAN, N. Conservação da biodiversidade em áreas protegidas. Rio de Janeiro: Editora FGV, 2006. 176p.

BRASIL. Lei Federal $\mathbf{n}^{\circ}$ 9.985, de 18 de setembro de 2000, que regulamenta o art. 225, § 1ำ, incisos I, II, III e VII da Constituição Federal, institui o Sistema Nacional de Unidades de Conservação da Natureza e dá outras providências.

BRASIL. IBAMA. Roteiro Metodológico para Elaboração de Plano de manejo para Reservas Particulares do Patrimônio Natural. Brasília: IBAMA, 2004, 95p.

BRASIL. IBAMA. Efetividade de gestão das Unidades de Conservação federais do Brasil. Brasília: IBAMA-WWF, 2007. 96p.

BRASIL. IBAMA. Unidades de Conservação Federais. Brasília: IBAMA, 2008.

BRITO, M.C.W. Unidades de conservação: intenções e resultados. Dissertação de Mestrado, Programa de Pós-Graduação em Ciência Ambiental da USP (PROCAM / USP), São Paulo: 1995.

DIEGUES, A.C.S. 0 mito moderno da natureza intocada. 6 ed. ampliada. São Paulo: Hucitec: Nupaub-USP/CEC. 2008

FUNDAÇÃO FLORESTAL DE SÃO PAULO. A Importância dos Planos de Manejo. Disponível em: http://www.fflorestal.sp.gov.br/planodemanejo.php , s/d. Acessado em: 30 maio 2010. 
Parques Nacionais Brasileiros: relação entre Planos de Manejo e a atividade ecoturística.

GIULIANI G. M. As Unidades de Conservação no Brasil e na Itália. Disponível em: http://www.ivt-rj.net/sapis/anais2005/mesas/mesa23.htm . Acesso em: 20 out. 2009.

KINKER, S. Ecoturismo e conservação da natureza em parques nacionais. Ed. Papirus, Campinas - SP, 2002 (Coleção turismo).

MILANO, M. S. Conceitos básicos e Princípios Gerais de Planejamento, Manejo e Administração de Unidades de Conservação. In: FBPN (org.) Planejamento e Manejo de Áreas Naturais Protegidas. FBPN. Guaraqueçaba. 2001

MORSELLO, C. Áreas protegidas públicas e privadas seleção e manejo. Annablume: São Paulo, 2006.

MOURA, L. A. A. de. Economia Ambiental. Gestão de Custos e Investimentos. São Paulo: Juarez de Oliveira, 2000, p. 5. In: In: VIANA, J. R. A. O Direito Ambiental e o princípio do desenvolvimento sustentável. Jus Navigandi, Teresina, ano 6, n. 57, jul. 2002.

OST, F. A natureza à margem da lei. Lisboa: Instituto Piaget. 1998. 400p.

PASQUALI, R. Parcerias público-privadas na gestão de serviços turísticos em parques nacionais: possibilidades para o Parque Nacional da Chapada dos Guimarães - MT. (Dissertação). Programa de Pós-graduação em Turismo e Hotelaria da Universidade do Vale do Itajaí. 2006.

QUINTAS, J. S. Educação e gestão ambiental pública. In: Edições IBAMA. Educação no processo de gestão ambiental: uma proposta de educação ambiental, transformadora e emancipatória. Brasília:I|BAMA, 2004.

RESERVA EXTRATIVISTA CAZUMBÁ-IRACEMA. Plano de Manejo. Disponível em: http://cazumba.org/index.php?Itemid=36\&id=25\&option=com content\&task=view Depositado em 31 de maio 2006. Acessado em: 31 de maio 2010.

ROCKTAESCHEL, B. M. M. M. Terceirização em áreas protegidas: estímulo ao ecoturismo no Brasil. São Paulo: Editora SENAC, 2006.

RYLANDS, A. B.; BRANDON, K. Unidades de Conservação brasileiras. Megadiversidade, vol. 1, $n$ 1. jul. 2005

VIANNA, L. P. De invisíveis a protagonistas: populações tradicionais e unidades de conservação. São Paulo: Annablume; FAPESP, 2008. 340p.

Anderson Alves Santos: Instituto Federal de Educação, Ciência e Tecnologia de Minas Gerais

Email: alvessanto@gmail.com

Link para o currículo Lattes: http://lattes.cnpq.br/7747265989770754

Data de submissão: 29 de outubro de 2010.

Data do aceite: 01 de janeiro de 2011. 